\title{
Aquifers productivity in the Pan-African context
}

\author{
Aretouyap Zakari ${ }^{1, *}$, Nouayou Robert ${ }^{1}$, Njandjock Nouck Philippe ${ }^{1}$ and Asfahani Jamal ${ }^{2}$ \\ ${ }^{1}$ Postgraduate School of Science, Technology and Geosciences, University of Yaounde I, \\ P.O. Box 812 Yaounde, Cameroon. \\ ${ }^{2}$ Applied Geophysics Division, Head Atomic Energy Commission, P.O. Box 6091, Damascus, Syria. \\ ${ }^{*}$ Corresponding author. e-mail: aretouyap@gmail.com
}

In this study, 50 Vertical Electrical Soundings (VES) were carried out in the region, including 14 near existing boreholes for comparison. Aquifer parameters of hydraulic conductivity and transmissivity were obtained by analyzing pumping test data from existing boreholes. An empirical relationship between hydraulic conductivity $(\mathrm{K})$ obtained from pumping test and both resistivity and thickness of the Pan-African aquifer has been established for these boreholes in order to calculate the geophysical hydraulic conductivity. The geoelectrical interpretation shows that almost all aquifers are made of the fractured portion of the granitic bedrock located at a depth ranging between 7 and $84 \mathrm{~m}$. The hydraulic conductivity varies between 0.012 and $1.677 \mathrm{~m} /$ day, the resistivity between 3 and $825 \Omega \mathrm{m}$, the thickness between 1 and $101 \mathrm{~m}$, the transmissivity between 0.46 and $46.02 \mathrm{~m}^{2} /$ day, the product $\mathrm{K} \sigma$ between $2.1 \times 10^{-4}$ and $4.2 \times 10^{-4}$.

\section{Introduction}

Depending on weather conditions, and geological and geomorphological contexts of each region, the water sector poses more difficulties. These difficulties may arise in terms of flood (too much water), dryness (very little water) or pollution (poor quality water). All these problems have a common consequence: the shortage of good quality water for domestic, agro-pastoral and industrial needs. In some semi-arid climate contexts, surface water has shown its limits due to climate aversion and poor spatial distribution of populations (Arétouyap et al. 2014). This explains the importance of groundwater in such regions and the interest that is brought to its potential exploration. The exploitation of this resource must be carried out with extreme diligence to ensure a long-term use (Asfahani 2007). Efficient management of groundwater resources depends on the accuracy in the detection and location of aquifers and in predicting their behaviour during the upcoming exploitation. Indeed, one of the general handicaps faced by the exploitation of new aquifers is the lack of information on their properties (permeability, transmissivity, etc.) due to the limitation of the number of pumping tests.

Geophysical methods such as Vertical Electrical Sounding (VES) technique can contribute significantly to the accuracy of the aquifer location and productivity, not only by developing its geometry but also by establishing a relationship between the hydrogeological and geo-electrical parameters. Indeed, since the late 1960s, many researchers, scientists, engineers and hydrologists have used the resistivity method to obtain useful information about the aquifers such as hydraulic conductivity, transmissivity, and flow. Some of these studies are summarized in table 1.

Asfahani (2012, 2013 and 2014) has recently proposed two other inexpensive alternative approaches based on the use of surficial VES technique to

Keywords. Aquifer depth; geoelectrical surveys; hydraulic conductivity; ordinary kriging; Pan-African context; pumping test. 
Table 1. Summarized table of literature review.

\begin{tabular}{|c|c|c|}
\hline Author & Salient features & $\begin{array}{c}\text { Application } \\
\text { country }\end{array}$ \\
\hline Jones and Bufford (1951) & Relationship between permeability and formation factor & USA \\
\hline Croft (1971) & Relationship between permeability and formation factor & USA \\
\hline Vincenz (1968) & Relationship between resistivity and well productivity & Mexico \\
\hline Ungemach et al. (1969) & Relationship between transmissivity and transverse resistance & India \\
\hline Scarascia (1976) & Assessment of the transmissivity through interpreting the electrical soundings & Italy \\
\hline Kelly (1977) & Correlation between saturated thickness resistivities and hydraulic conductivities & England \\
\hline Mazáč and Landa (1979) & Relationship between aquifer transmissivity and transverse resistance & Poland \\
\hline Athavale et al. (1992) & Measurement of natural recharge & India \\
\hline Frohlich et al. (1996) & Electrical hydraulic conductivity correlation in fractured crystalline bedrock & USA \\
\hline Huntley (1986) & Relations between permeability and electrical resistivity in granular aquifers & India \\
\hline Emenike (2001) & Groundwater exploration in a sedimentary environment & Nigeria \\
\hline Yang and Lee (2002) & Hydrogeological studies & Taiwan \\
\hline Chandra et al. (2004) & Groundwater exploration in hard rock areas & India \\
\hline Asfahani (2007) & Determination of the characteristics of the Neogene aquifer & Syria \\
\hline Nejad (2009) & Study of the water potential & Iran \\
\hline Anomohanran (2013) & Study of the water potential & Nigeria \\
\hline
\end{tabular}

compute the aquifer hydraulic conductivity. His alternative approaches have been successfully applied for characterizing the transmissivity of the Quaternary and Paleogene aquifers in the semi-arid Khanasser valley region, northern Syria.

The main objectives of this paper are, therefore, the following:

1. Detecting and locating the aquifers in the PanAfrican region by applying electrical resistivity surveys.

2. Characterizing those aquifers in terms of hydraulic conductivity, transmissivity, depth, thickness and resistivity.

3. Building up thematic maps of those mentioned characteristics by using the geostatistical ordinary kriging method.

\section{Materials and methods}

\subsection{Study area}

This study is carried out in the Pan-African region of Adamawa, located in the heart of central Africa between $6^{\circ}-8^{\circ} \mathrm{N}$ latitude and $11^{\circ}-16^{\circ} \mathrm{E}$ longitude (figure 1). It extends over a length of about $410 \mathrm{~km}$ from west to east between Nigeria and the central African Republic, for a total area of $67,827 \mathrm{~km}^{2}$. From March to October, the region receives an average rainfall of $1540 \mathrm{~mm}$ per year. The temperature is moderate with an annual average around $25^{\circ} \mathrm{C}$ (Arétouyap et al. 2014). On the hydrological level, the Adamawa region is called 'the water tower of Cameroon' because it feeds three of the four major watersheds of this country, namely the lake Chad basin, the Niger basin in the north and the Sanaga Atlantic basin in the south.

The study area consists of two major geological domains:

- The former basement that includes highly metamorphosed formations (migmatitic, gneiss and mica), and intrusive bodies composed of granites;

- The covering formations that include: red lateritic soils, sedimentary (sandstones and conglomerates) and volcanic (basalt and trachyte) rocks.

This region is the stool of a Pan-African granitegneissic basement, represented by granites, gneisses and Pan-African migmatites. Geological formations encountered are basalts, trachytes and trachyphonolites based mostly on concordant and discordant alkaline granites (Toteu et al. 2000). There are two major fractures slanted towards in two directions:

- The first oriented $\mathrm{N} 30^{\circ} \mathrm{E}$ (most common) is that of the 'Cameroon volcanic line';

- The second oriented $\mathrm{N} 70^{\circ} \mathrm{E}$, is the 'Adamawa line' or 'shear area of Adamawa'.

The soils of the region are lateritic and classified into two types (Segalen 1967; Toteu et al. 2004): red soils derived from ancient metamorphic rocks and red soils formed on old basalts.

\subsection{VES acquisition and data processing}

Fifty VES have been carried out in the study region (figure 2), by using Schlumberger array in order 

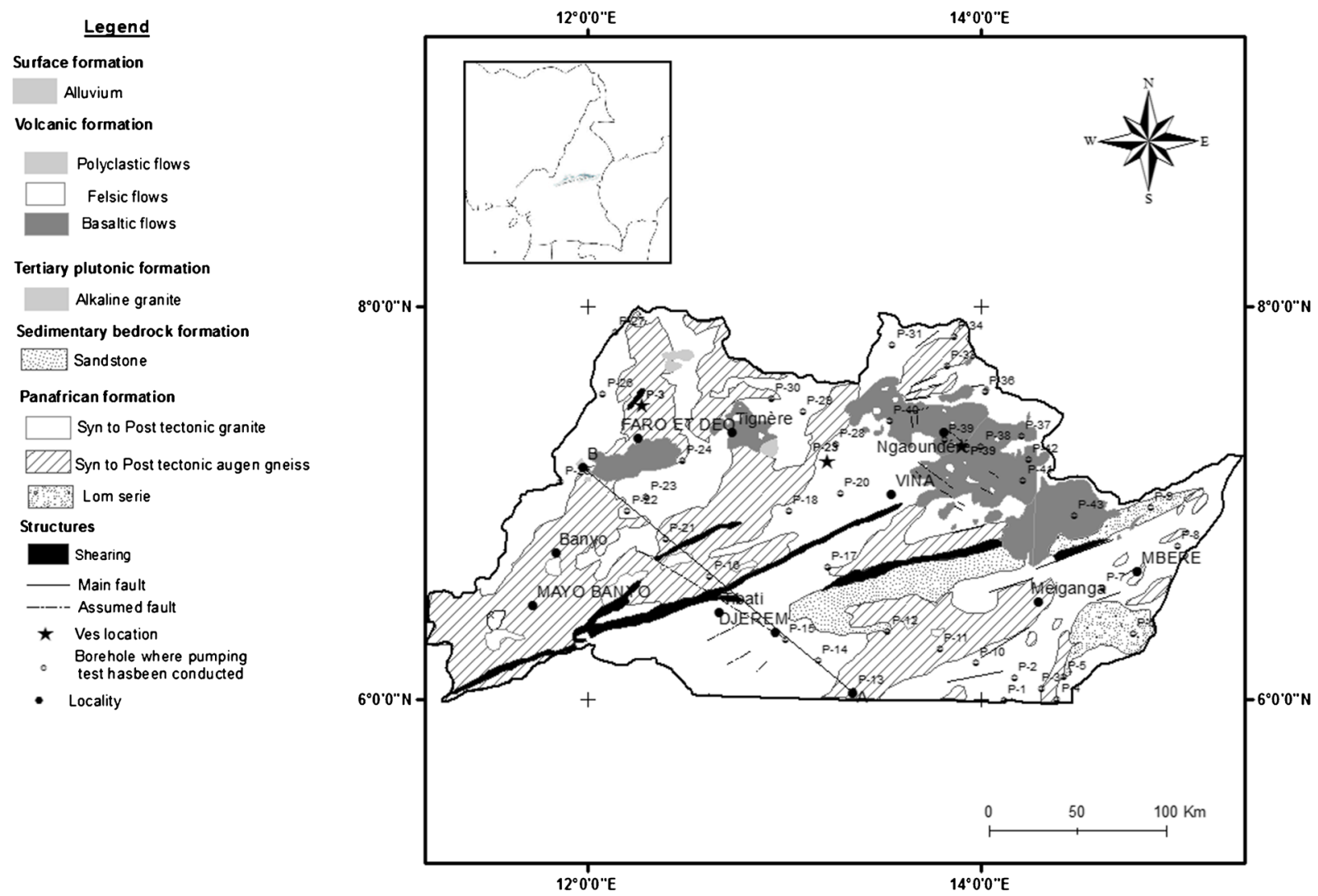

Figure 1. Simplified geological map of the study area.

to detect the aquifers and determine their electrical characteristics (Dar-Zarrouck parameters). ABEM terrameter (SAS 1000) was used to conduct those VES measurements, with current electrode separation (AB) varying from 1 to $300 \mathrm{~m}$ in successive steps. The SAS 1000 measures directly the resistance $\Delta V / I$, and apparent resistivity $\rho_{a}$ is subsequently computed according to equation (1) (Dobrin 1976).

$$
\rho_{a}=\frac{2 \pi}{\left(\frac{1}{A M}-\frac{1}{B M}-\frac{1}{A N}+\frac{1}{B N}\right)} \frac{\Delta V}{I},
$$

where $I$ is the current introduced into the earth by current electrodes, $A$ and $B$, and $\Delta V$ are the potentials measured between the potential electrodes $M$ and $N$.

The apparent resistivity values $\rho_{a}$ obtained by increasing the electrode spacing around a fixed point are plotted against half electrode separation $A B / 2$ in order to establish the field resistivity curve.

Interpretation of field resistivity curves is made by a curve matching technique using master curves (Asfahani 2011) for the initial determination of thicknesses and resistivities of corresponding layers (initial approximate model). The parameters of this approximate model were accurately interpreted using an inverse technique program, until a goodness-of-fit between the field resistivity curve and the theoretical regenerated curve was obtained (Zohdy 1989; Zohdy and Bisdorf 1989). The quantitative interpretation of VES data has been made by adapting two main hypotheses as follows (Anomohanran 2013):

- the earth is horizontal, with the last layer being of infinite thickness;

- each layer is electrically homogeneous and isotopic.

The ordinary kriging technique is used to interpolate the hydrogeophysical investigation results in the overall region, even in the locations where VES measurements were not conducted. This kriging method involves three steps (Gorai and Kumar 2013):

1. Exploratory data analysis: the main role of this step is to check data consistency, remove outliers and identify statistical distribution where data came from, because kriging methods work best for normal distribution data. Normal data distribution is decided when the mean and the median are very similar. However, high skewness 

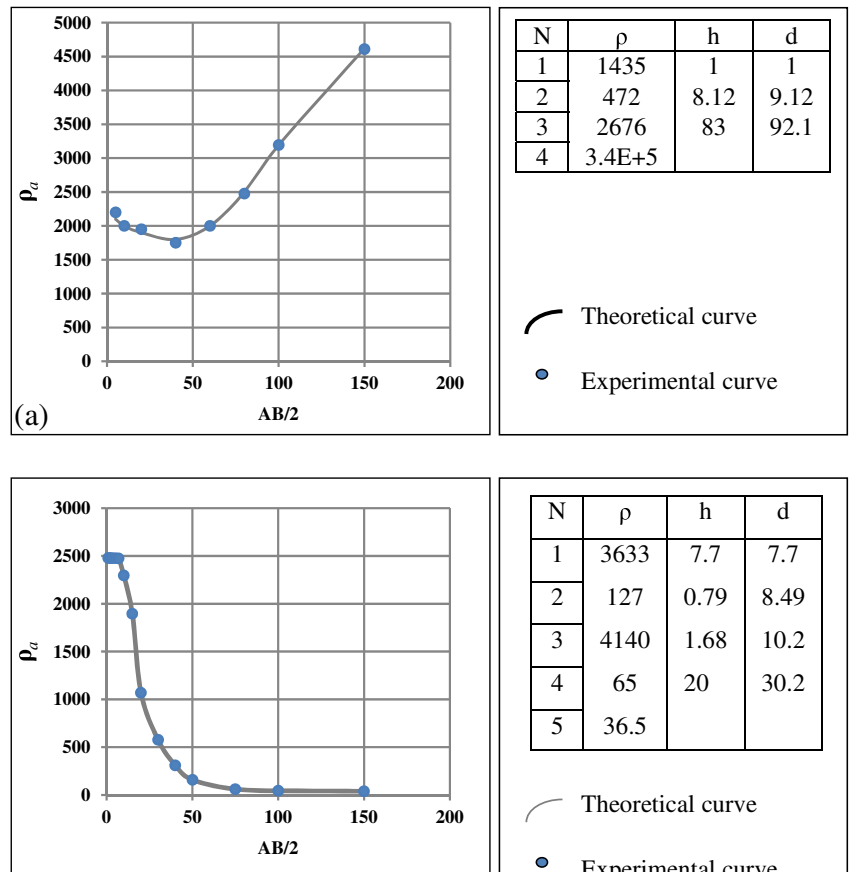

(b)

\begin{tabular}{|c|c|c|c|}
\hline $\mathrm{N}$ & $\rho$ & $\mathrm{h}$ & $\mathrm{d}$ \\
\hline 1 & 3633 & 7.7 & 7.7 \\
\cline { 1 - 1 } 2 & 127 & 0.79 & 8.49 \\
\cline { 1 - 1 } 3 & 4140 & 1.68 & 10.2 \\
\cline { 1 - 1 } 4 & 65 & 20 & 30.2 \\
\cline { 1 - 1 } 5 & 36.5 & & \\
\hline
\end{tabular}

Theoretical curve

- Experimental curve

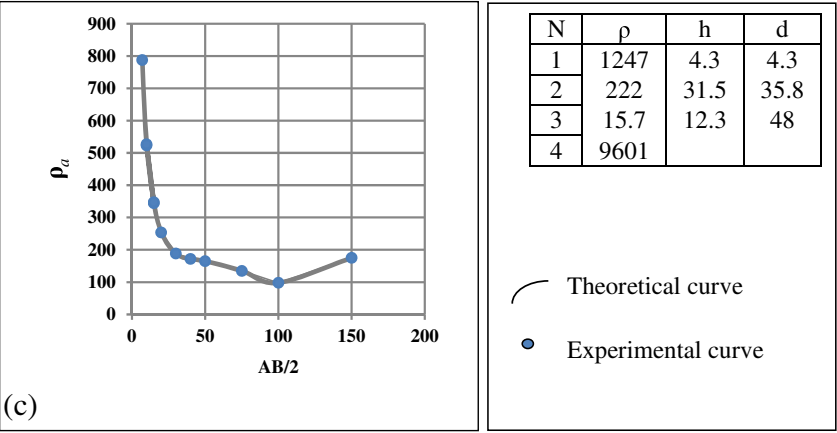

Figure 2. Examples of resistivity sounding curves with their interpretative models, measured on points of existing boreholes. (a) Resistivity curve measured at BekaMangari (P-3). (b) Resistivity curve measured at Kona Gaouri (P-23). (c) Resistivity curve measured at Nyambaka (P-39).

values indicate the existence of outliers, which are very high or low measured values compared to the dataset. The outliers are caused by a bad measurement or a bad recording, and must be transformed when they exist.

2. Structural data analysis: spatial correlation or dependence in the dataset will be quantified by using variograms. Kriging relates the variogram, the half expected squared difference between paired data values $z(x)$ and $z(x+h)$ to the distance lag $h$, by which locations are separated (equation 2).

$$
\gamma(h)=\frac{1}{2} E[z(x)-z(x+h)]^{2} .
$$

For discrete variables, this function can be written as shown in equation (3).

$$
\gamma(h)=\frac{1}{2 N(h)} \sum_{i=1}^{N(h)}\left[z\left(x_{i}\right)-z\left(x_{i}+h\right)\right]^{2}
$$

where $z\left(x_{i}\right)$ is the value of the variable $Z$ at location $x_{i}, h$ the lag, and $N(h)$ the number of pairs of VES locations separated by $h$. For irregular data, it is rare for the distance between the location pairs to be exactly equal to $h$. A variogram plot is obtained by calculating values of the variogram at different lags. These values are thereafter fitted with a theoretical model. The models provide information about the spatial structure as well as the input parameters for the kriging interpolation.

3. Prediction: seven variogram models (exponential, spherical, Gaussian, magnetic, gravimetric, pentaspherical and quadratic) were tested for each studied parameter (depth, thickness, hydraulic conductivity, and transmissivity of the aquifer) in order to select the best-fitted one. Predictive performances of the fitted models are checked on the basis of cross validation tests. The values of mean error (ME), mean square error (MSE), root mean square error (RMSE), average standard error (ASE), and root mean square standardized error (RMSSE) are estimated to ascertain the performance of the developed models. If the predictions are unbiased, the ME should be almost nil. But because of its weaknesses due to its dependence upon the scale of the data and to its indifference to the wrongness of variogram, ME is generally standardized by the MSE, being ideally zero.

However, RMSE and ASE should be calculated to indicate if the prediction errors were correctly assessed in the case where they are close. Otherwise, if the RMSE is less than the ASE (or RMSSE $<1$ ), then the variability of the predictions is overestimated; and if the RMSE is greater than the ASE (or RMSSE > 1), then the variability of the predictions is underestimated. Once the best model is selected, it is used to draw the thematic map that provides the spatial distribution of the parameter to be estimated. All these errors are expressed by equations (4-8) below (Goovaerts 1997; Gorai and Kumar 2013).

$$
\begin{aligned}
\mathrm{ME} & =\frac{1}{N} \sum_{i=1}^{N}\left[Z^{*}\left(x_{i}\right)-Z\left(x_{i}\right)\right] \\
\mathrm{MSE} & =\frac{1}{N} \sum_{i=1}^{N}\left[\frac{Z^{*}\left(x_{i}\right)-Z\left(x_{i}\right)}{\sigma^{2}\left(x_{i}\right)}\right]
\end{aligned}
$$




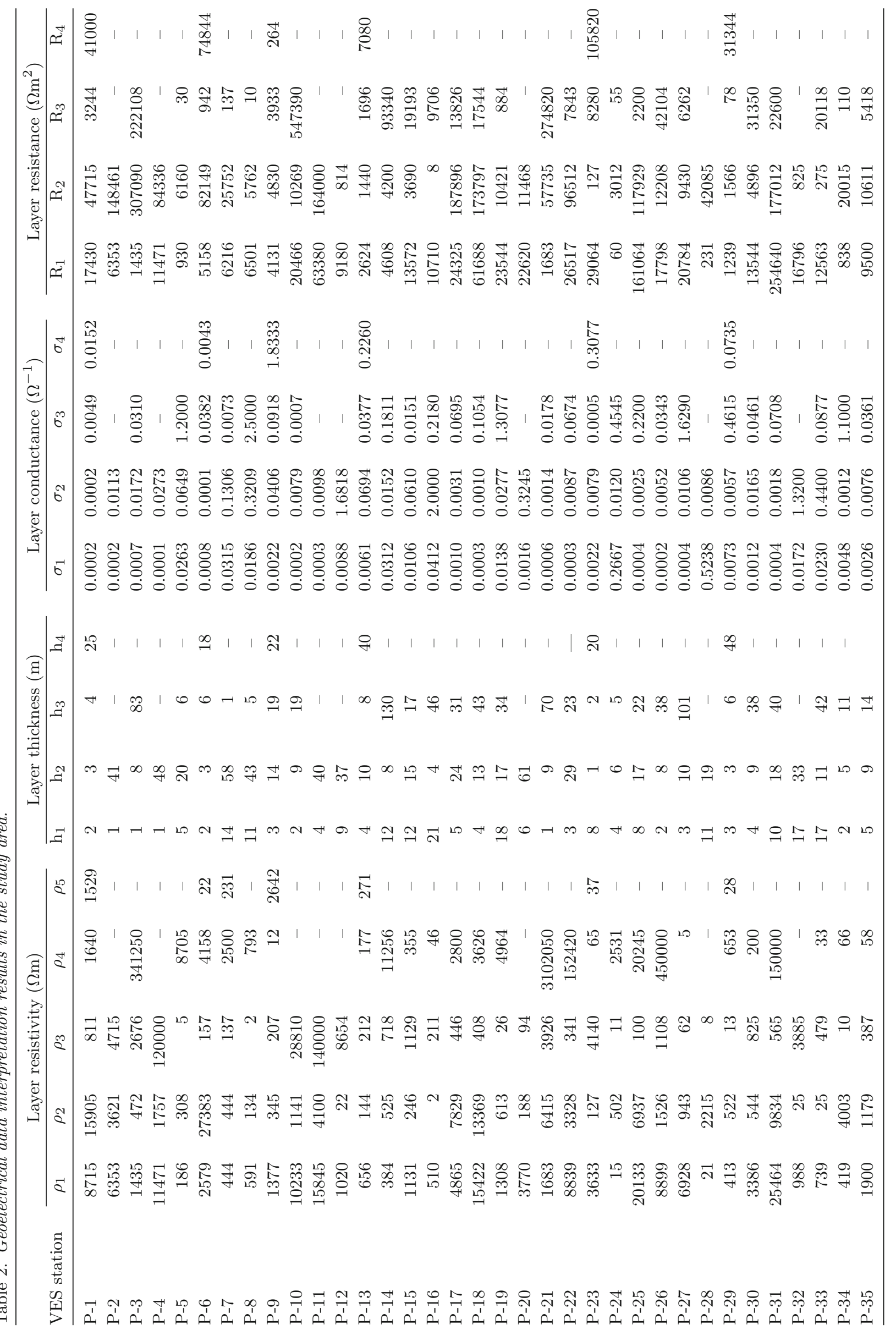




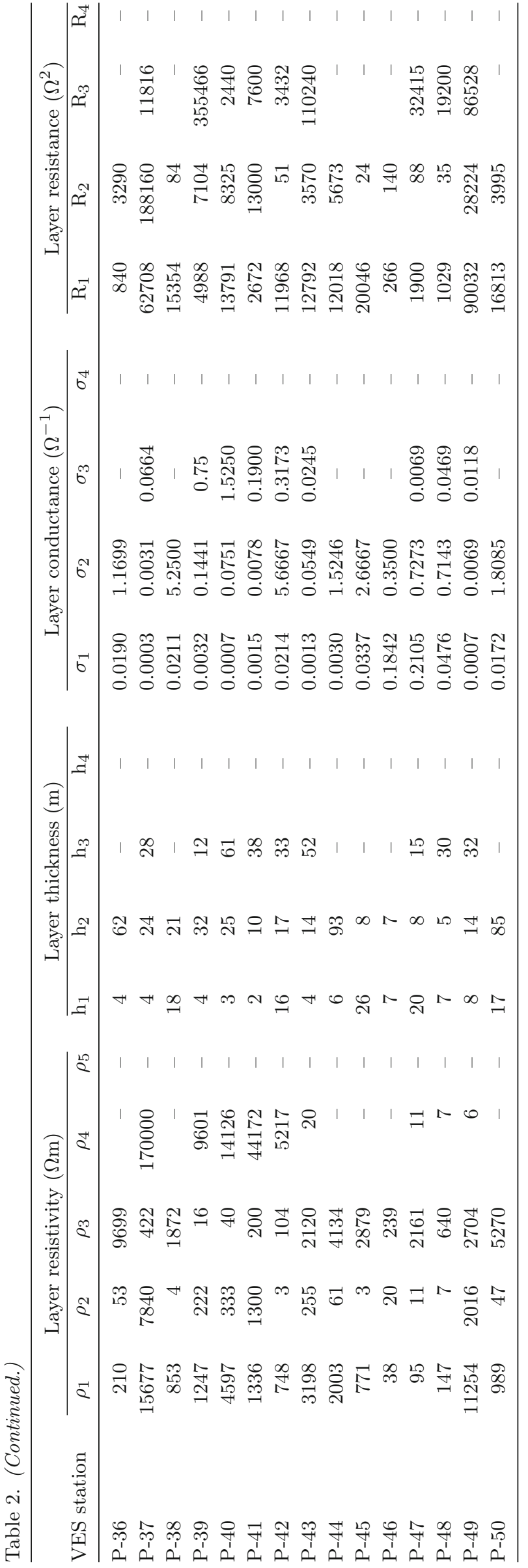

$$
\begin{gathered}
\mathrm{RMSE}=\sqrt{\frac{1}{N} \sum_{i=1}^{N}\left[Z^{*}\left(x_{i}\right)-Z\left(x_{i}\right)\right]^{2}} \\
\mathrm{ASE}=\sqrt{\frac{1}{N} \sum_{i=1}^{N} \sigma^{2}\left(x_{i}\right)} \\
\mathrm{RMSSE}=\sqrt{\frac{1}{N} \sum_{i=1}^{N}\left[\frac{Z^{*}\left(x_{i}\right)-Z\left(x_{i}\right)}{\sigma^{2}\left(x_{i}\right)}\right]^{2}} .
\end{gathered}
$$

where $\sigma^{2}\left(x_{i}\right)$ is the kriging variance for location $x_{i}, Z^{*}\left(x_{i}\right)$ and $Z\left(x_{i}\right)$ are the estimated and the measured values of the parameter at the location $x_{i}$, respectively.

\subsection{The hydrogeophysical model parameters}

The hydraulic conductivity $(\mathrm{K})$ of an aquifer is the main hydrogeological property for the overall region. It refers to the ability of the aquifer to receive the infiltrated water, and expressed in $\mathrm{m} /$ day. Fourteen available boreholes exist in the study region (figure 1), where traditional pumping tests have been conducted, and enabled to evaluate the hydraulic conductivity values on those boreholes.

This paper applies the technique already developed by Asfahani (2007). This technique consists of the following steps:

1. Plotting a calibration line of the empirical relationship between the transverse resistance $R$ of the aquifer obtained by VES interpretations, carried out in the 14 VES locations near the boreholes, and $K \sigma$, where $K$ is the hydraulic conductivity parameters obtained by pumping tests from the 14 available boreholes in the study area.

2. Determining the Dar-Zarrouck parameters (transverse resistance $R$ and longitudinal conductance $S$ ) given by equations (9) and (10) for the other 36 VES points, where no borehole exists.

$$
\begin{gathered}
R=\sum_{i=1}^{n} h_{i} \rho_{i} \\
S=\sum_{i=1}^{n} \frac{h_{i}}{\rho_{i}}
\end{gathered}
$$

where $h_{i}$ and $\rho_{i}$ are the thickness and the resistivity of $i$ th layer in the section, respectively.

The transmissivity at each VES location is deduced by equation (11), by taking into consideration the transmissivity and the transverse 


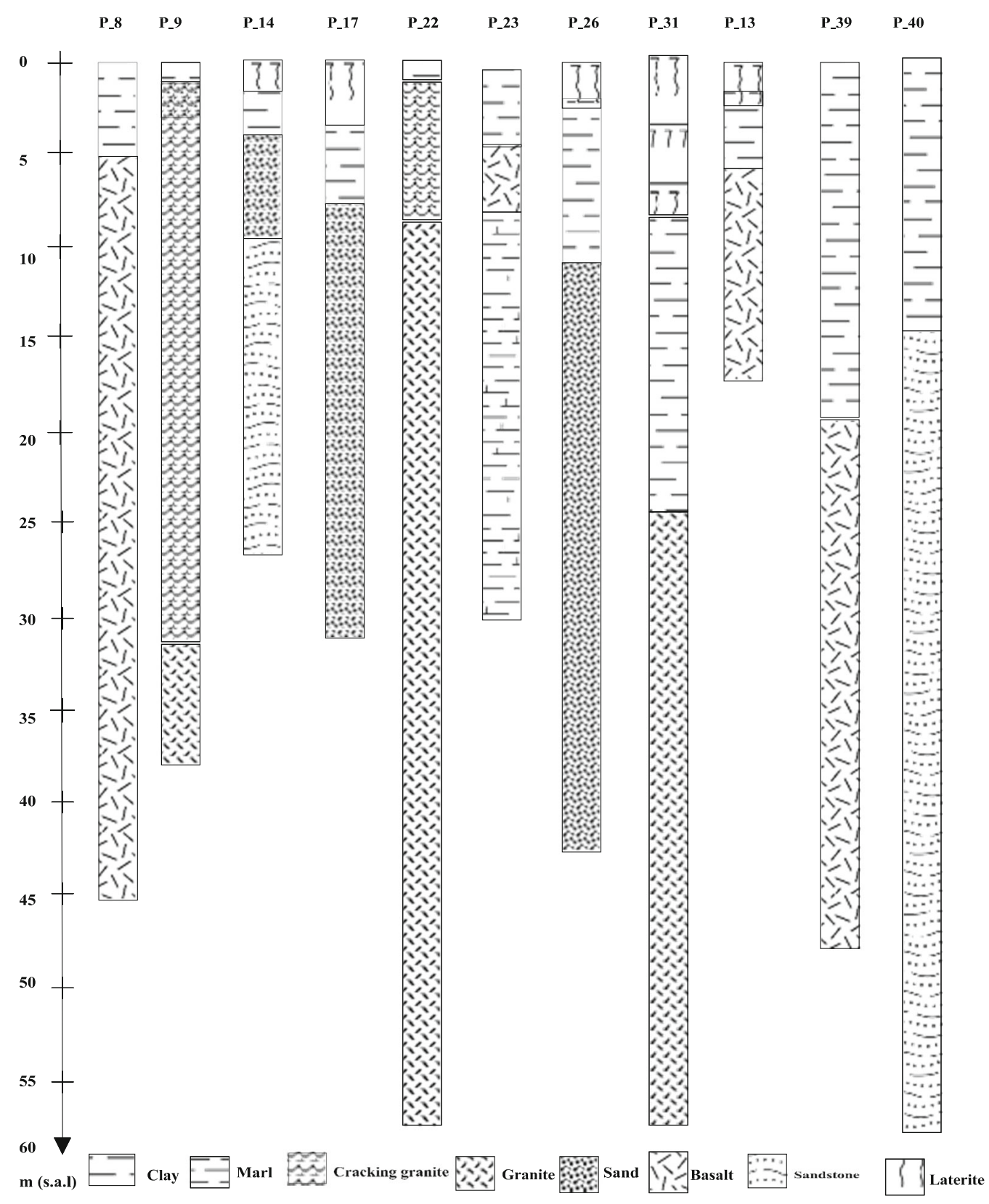

Figure 3. Lithological sections of 11 boreholes logged to highlight the vertical variation of the lithology.

conductance for each layer (equations 12 and $13)$.

$$
T=K \sigma R=K h
$$

where $K$ is the hydraulic conductivity of the aquifer, $\sigma$ its electric conductivity, $R$ its transverse resistance and $h$ its depth.

$$
S_{i}=\sigma_{i} h_{i}
$$

where $\sigma_{i}$ is the layer conductivity.

$$
\operatorname{Tr}_{i}=K_{i} h_{i}
$$

where $K_{i}$ is the hydraulic conductivity of the $i$ th layer with thickness $h_{i}$.
3. Using the empirical relationship explained in step 1 to compute $K \sigma$ and, consequently, $K$ for each VES location.

\section{Results and discussion}

Fifty VES with Schlumberger configuration have been carried out in the study area and interpreted. Figure 2 shows the resistivity curves obtained at 3 of the 14 existing boreholes (P-3, P-23, and P-39) and their interpretative models, and a summary of the results for all the sounding stations is presented in table 2. The VES interpreted results have been mainly calibrated through referring to the 


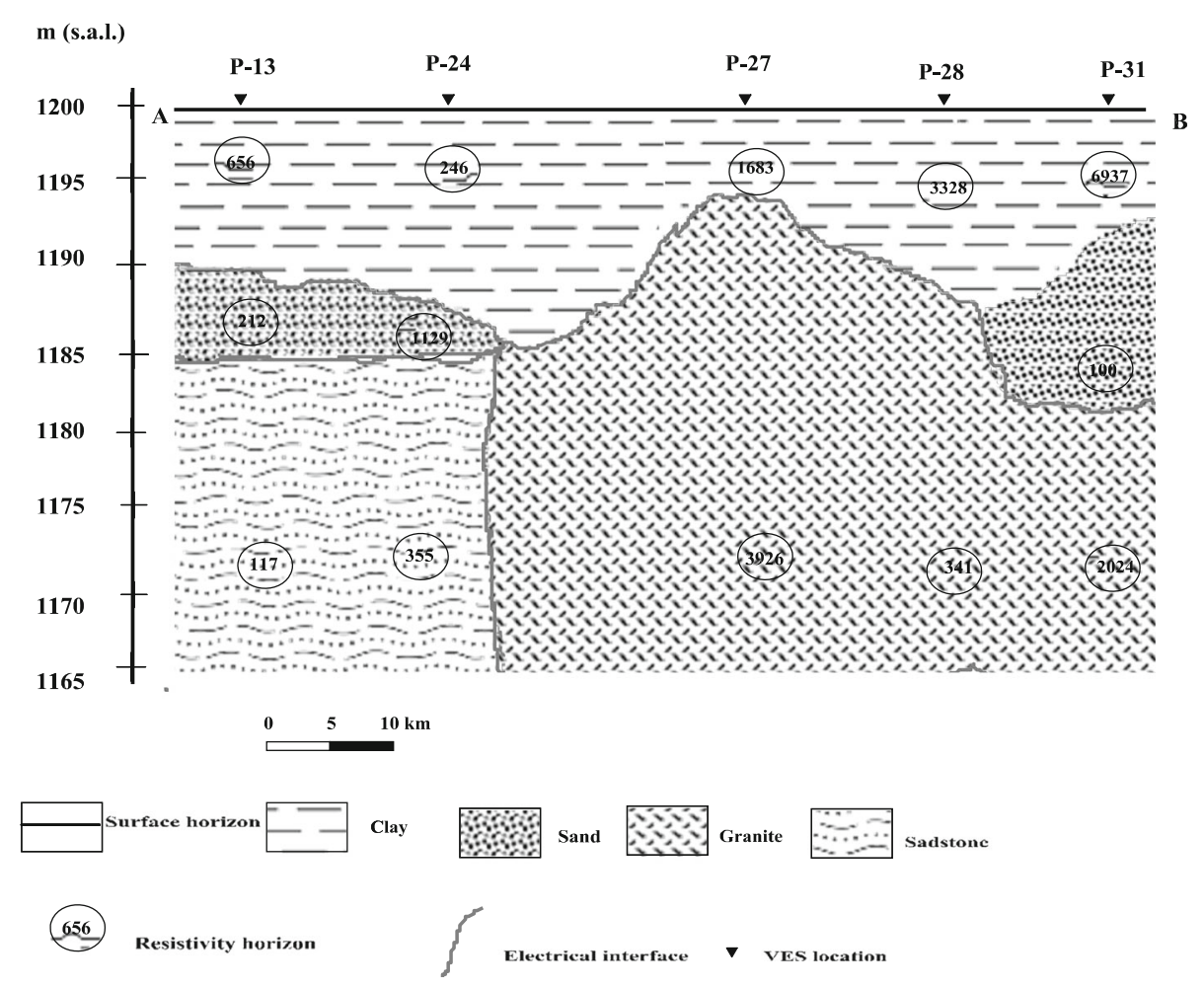

Figure 4. Lithological cross-section along the profile A-B.

geoelectrical response acquired from surface outcrops of different formations and to the lithological information obtained from eleven boreholes logged on the locations of P-8, P-9, P-14, P-17, P-22, P-23, P-26, P-31, P-33, P-39 and P-40 (figure 3).

The quantitative interpretation allows the construction of the lithological cross-section along the profile $\mathrm{A}-\mathrm{B}$ that matches stations $\mathrm{P}-24, \mathrm{P}-27$, P-28 and P-31 in southeast-northwest direction (figure 4).

This interpretation is used to detect and locate the aquifers and to determine the lithology of each VES location. The application of the approach developed by Asfahani (2007) enables to establish an empirical relationship between $K \sigma$ and $R$ from the 14 boreholes existing in the region (equation 14) as shown in figure 5.

$$
K \sigma=-10^{-14} R+5.10^{-9} .
$$

The application of equation (14) enables to compute the $K \sigma$ in all the VES locations and consequently derive the hydraulic conductivity $K$ in each VES location.

The study of the profile $\mathrm{A}-\mathrm{B}$ indicates the existence of two types of geological array:

1. The first type is located at the middle of the profile and has three geological horizons. The first horizon is laterite or topsoil with a thickness varying between 0.5 and $1.5 \mathrm{~m}$. Laterite generally has a high resistivity up to $4000 \Omega \mathrm{m}$.

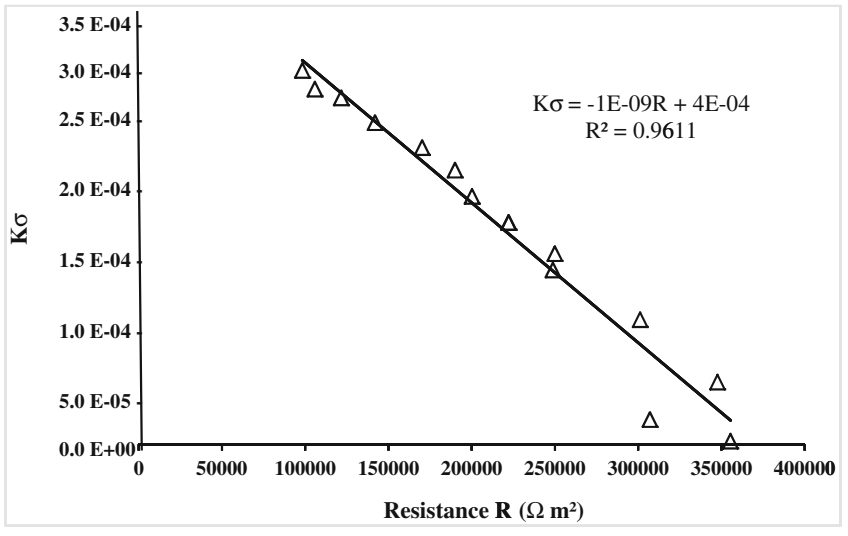

Figure 5. Calibration line of the empirical relation between $R$ and $K \sigma$.

The second horizon is a clayey soil. Its thickness varies from 5 to $15 \mathrm{~m}$, and its resistivity ranges between 200 and $7000 \Omega \mathrm{m}$. The third horizon is the granitic bedrock. Its upper part represents the aquifer when it is altered or cracked. Its thickness varies between 1 and $101 \mathrm{~m}$, and depending on the degree of the alteration, its resistivity varies between 3 and $825 \Omega \mathrm{m}$. When this horizon is not fractured, it is impermeable and constitutes the Pan-African base. In this case, its resistivity can reach thousands of ohm-meters.

2. The second type of geological array is observed at the ends of the profile and has four geological 
horizons. The first and the second horizons remain laterite/topsoil and clayey soil with the same proprieties, respectively. The third horizon is a sandy soil. Its thickness varies from 1 to 15 $\mathrm{m}$, and its resistivity ranges between 100 and $1300 \Omega \mathrm{m}$. In the southwest region, the fourth horizon representing the aquifer is composed of sandstone. Its thickness varies between 20 and $61 \mathrm{~m}$, and its resistivity varies between 47 and $355 \Omega \mathrm{m}$.

In general, the Pan-African aquifer in the study area is made of cracked upper part of granite or sandstone. This is the third or the fourth geoelectrical horizon.
The thickness of this Pan-African aquifer varies between 1 and $101 \mathrm{~m}$, with an average of $34.16 \mathrm{~m}$ and a standard deviation (SD) of $22.67 \mathrm{~m}$. Its resistivity varies between 3 and $825 \Omega \mathrm{m}$ with an average of $228.48 \Omega \mathrm{m}$ and an SD of $215.87 \Omega \mathrm{m}$. Figures 6 and 7 show the maps of resistivity and thickness variation of this Pan-African aquifer in the study area, respectively. The resistivity map indicates the presence of a low-resistivity zone, reflecting the potential direction of groundwater from north to south, and from northeast (where the recharge area is located) to southeast.

Table 3 indicates the properties of the aquifer at the 3 of 14 points (Beka-Mangari, Kona-Gaouri, and Nyambaka) where pumping tests were carried

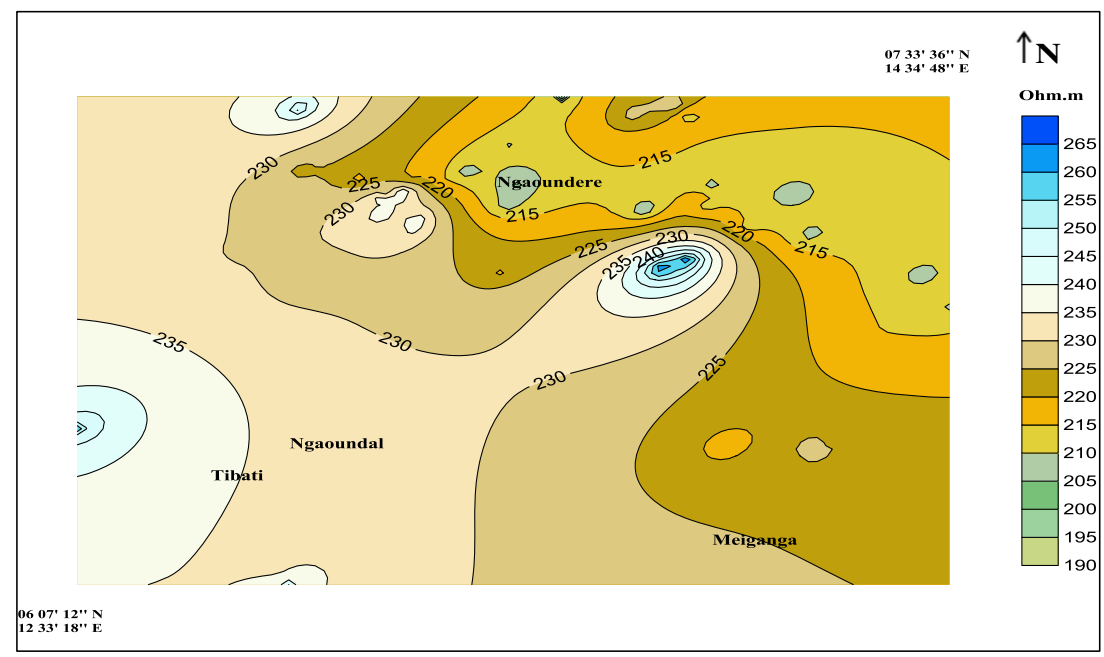

Figure 6. Thematic map of the aquifer resistivity.

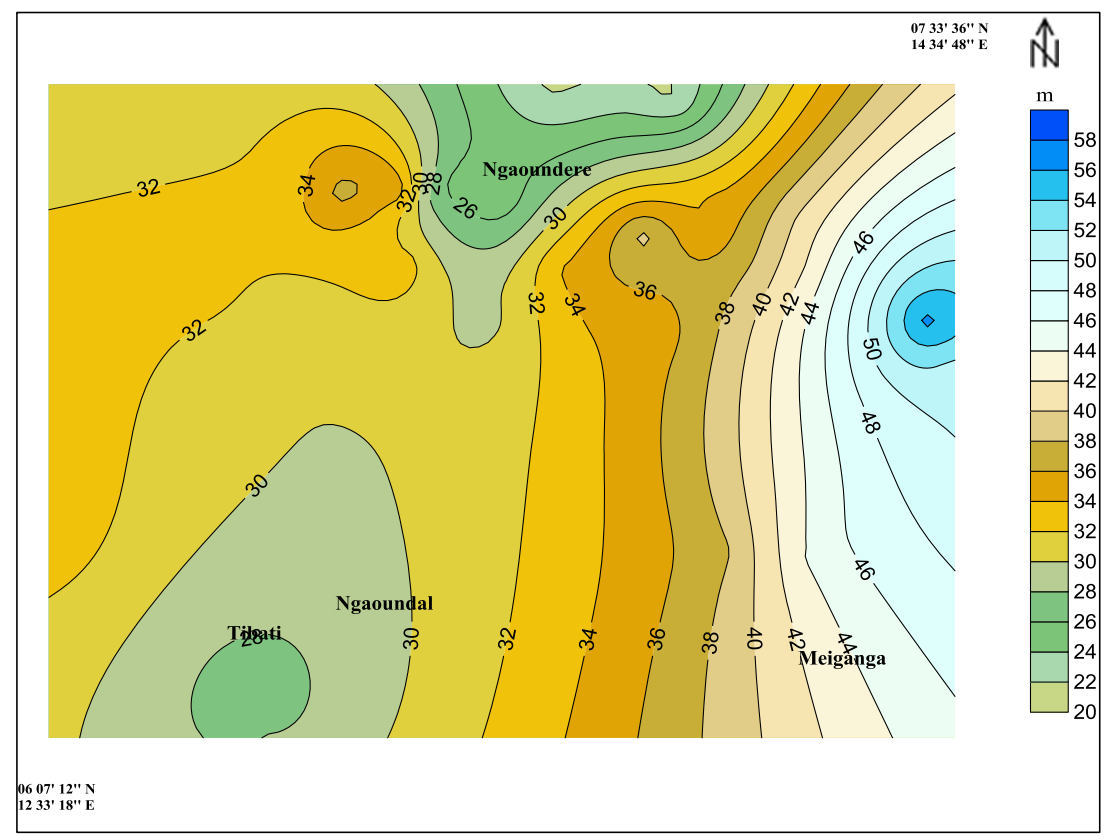

Figure 7. Thematic map of the aquifer thickness. 
Table 3. Aquifer properties of three existing boreholes in the study area.

\begin{tabular}{|c|c|c|c|c|}
\hline & Parameter & $\begin{array}{c}\text { Beka-Mangari } \\
\qquad(\mathrm{P}-3)\end{array}$ & $\begin{array}{c}\text { Kona Gaouri } \\
(\mathrm{P}-23)\end{array}$ & $\begin{array}{c}\text { Nyambaka } \\
(\mathrm{P}-39)\end{array}$ \\
\hline 1 & Hydraulic conductivity $K\left(\mathrm{~m} \cdot \mathrm{day}^{-1}\right)$ obtained from pumping test & 0.15 & 0.79 & 0.21 \\
\hline 2 & Aquifer resistivity $\rho(\Omega \mathrm{m})$ & 472 & 48 & 28 \\
\hline 3 & Aquifer thickness $h(\mathrm{~m})$ & 8.4 & 16.2 & 11.8 \\
\hline 4 & Longitudinal conductance $S\left(\Omega^{-1}\right)$ & 0.017324 & 0.3375 & 0.421 \\
\hline 5 & Transverse resistance $R\left(\Omega \mathrm{m}^{2}\right)$ & 307090 & 105820 & 355466 \\
\hline 6 & $\mathrm{~K} / \sigma\left(\times 10^{3}\right)$ & 1.11 & 2.21 & 0.163 \\
\hline 7 & $\mathrm{~K} \sigma\left(\times 10^{-5}\right)$ & 2.00 & 0.285 & 26 \\
\hline 8 & Aquifer transmisivity $\operatorname{Tr}_{\mathrm{i}}\left(\mathrm{m}^{2} \cdot\right.$ day $\left.^{-1}\right)$ & 1.2489 & 12.861 & 2.4214 \\
\hline 9 & Hydraulic conductivity $K\left(\mathrm{~m} \cdot\right.$ day $\left.^{-1}\right)$ derived from VES measurements & 0.148 & 0.779 & 0.205 \\
\hline
\end{tabular}

Table 4. Characteristics of the Pan-African aquifer in the study area.

\begin{tabular}{|c|c|c|c|c|c|c|}
\hline & $h(\mathrm{~m})$ & $\rho(\Omega \mathrm{m})$ & $\mathrm{T}_{\mathrm{ri}}\left(\mathrm{m}^{2} /\right.$ day $)$ & $K(\mathrm{~m} /$ day $)$ & $S\left(\Omega^{-1}\right)$ & $K \sigma\left(\times 10^{-4}\right)$ \\
\hline Min & 1 & 3 & 0.46 & 0.012 & 0.004 & 1.46 \\
\hline Max & 101 & 825 & 46.02 & 1.677 & 5.25 & 428.54 \\
\hline Average & 34.16 & 228.48 & 15.46 & 0.456 & 0.61 & 28.49 \\
\hline $\mathrm{SD}$ & 22.67 & 215.87 & 10.33 & 0.400 & 0.9 & 99.04 \\
\hline
\end{tabular}

out. The values of the resistivity of the aquifer vary hugely 28 (P-39) to $472 \Omega \mathrm{m}(\mathrm{P}-3)$. This is mainly explained by the nature of the aquifer studied. Indeed, contrary to sedimentary aquifers that are generally continuous, base aquifers are rather discontinuous and the value of their resistivity depends mainly on the degree of the bedrock fracturing or alteration. The granitic bedrock is then more fractured in Nyambaka (P-39) than Beka-Mangari (P-3).

Exact agreement for these three borehole locations is noted between the hydraulic conductivity derived from the geoelectrical data interpretation (parameter 9) and that obtained by pumping tests (parameter 1), as shown in table 4. Parameter 8 indicates the computed transmissivity of the aquifer by means of the geoelectrical parameters mentioned previously. Therefore, knowing the hydraulic conductivity from the pumping tests from the existing boreholes and $R$ (or $S$ ) from the geoelectrical data interpretation, the transmissivity $\mathrm{T}_{\mathrm{r}}$ and its variation from one place to another (including areas where borehole data are not available) have been evaluated through establishing an empirical relationship between those parameters, as explained previously. The transmissivity values determined from geoelectrical measurements according to equation (11) and shown in figure 8 are generally low over the entire area due to the known water scarcity in the study area. The transmissivity values vary between 0.46 and $46.02 \mathrm{~m}^{2}$.day ${ }^{-1}$, with an average of 15.46 $\mathrm{m}^{2} \cdot$ day $^{-1}$ and an SD of $10.33 \mathrm{~m}^{2}$.day ${ }^{-1}$. Comparison of figure 8 (transmissivity) with figure 7 (thickness of Pan-African aquifer) shows that areas underlain by relatively thick aquifer materials have higher transmissivity values than areas underlain by relatively thin aquifer materials. This relationship is expected, because transmissivity is a linear function of aquifer thickness, since hydraulic conductivity is assumed to be constant (Asfahani 2007).

Table 3 shows that aquifer resistivity which is higher in Beka-Mangari is the highest contrary to the transmissivity that is the lowest. Certainly, transmissivity is a linear function of resistivity according to equations (9 and 11). But it also depends on the aquifer thickness and hydraulic. This can also be explained by the geological composition of the soil.

Figure 9 shows the hydraulic conductivity map of the study area, where the values of this parameter range between 0.012 and 1.677 m.day $^{-1}$, with an average of 0.456 m.day $^{-1}$ and an SD of 0.400 m.day ${ }^{-1}$.

According to the product of $K \sigma$, the study area has two main trends as shown in figure 10: a low$K \sigma$ value zone in the centre and a high-value zone around the study area. The product of $K \sigma$ varies very slightly in the study area. It ranges from $2.1 \times 10^{-4}$ to $4.2 \times 10^{-4}$, with an average of $3.47 \times$ $10^{-4}$ and an SD of $0.84 \times 10^{-4}$. In light of the different geoelectrical results gathered, the characteristics of the Pan-African aquifer in the study area are summarized in table 4.

The aquifer depth varies generally from 14 to $70 \mathrm{~m}$ with most localities around $34 \mathrm{~m}$ (figure 11). Given the accessibility of aquifers (no huge depths), the 


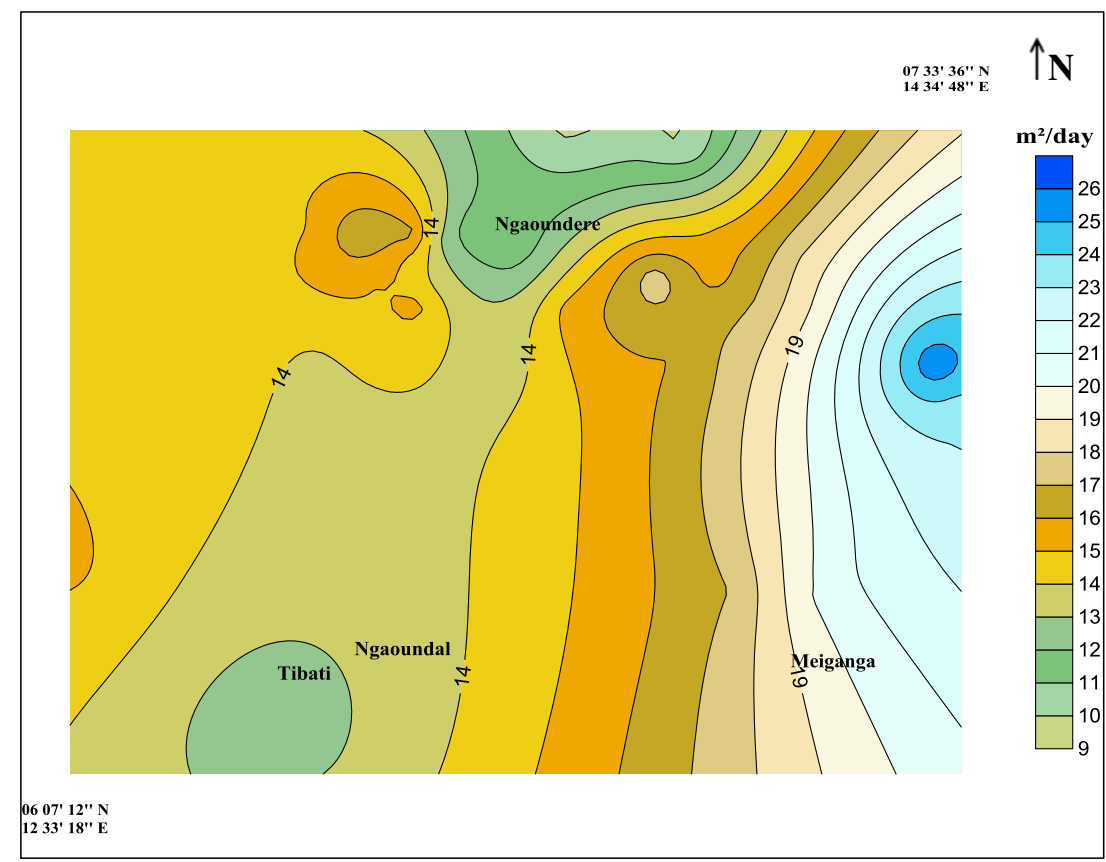

Figure 8. Thematic map of transmissivity.

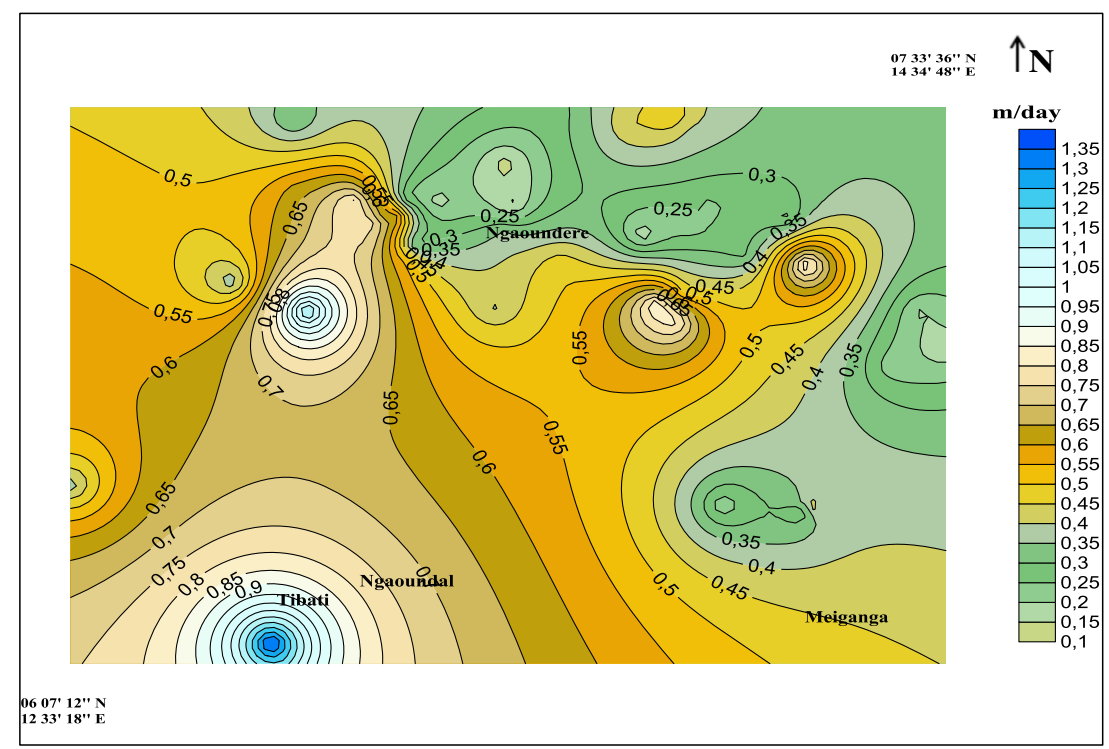

Figure 9. Thematic map of hydraulic conductivity.

main criteria for siting a borehole or a well are the hydraulic conductivity (for the ability to recharge) and physicochemical properties (for potability). The second criterion will be investigated during imminent studies while figure 10 shows that the northern part of the study area is more conductive and better rechargeable.

The knowledge of the characteristics of the studied parameters in the study area is important for integration in a scientific methodology oriented towards the optimum exploitation of the Pan-African aquifer.

The equation used to determine hydrodynamic parameters from Dar-Zarrouck electrical parameters is an empirical relationship. In order to increase its reliability, the study area should be divided into small areas according to their respective geological features. For this, the other experimental boreholes will be drilled in the region. 


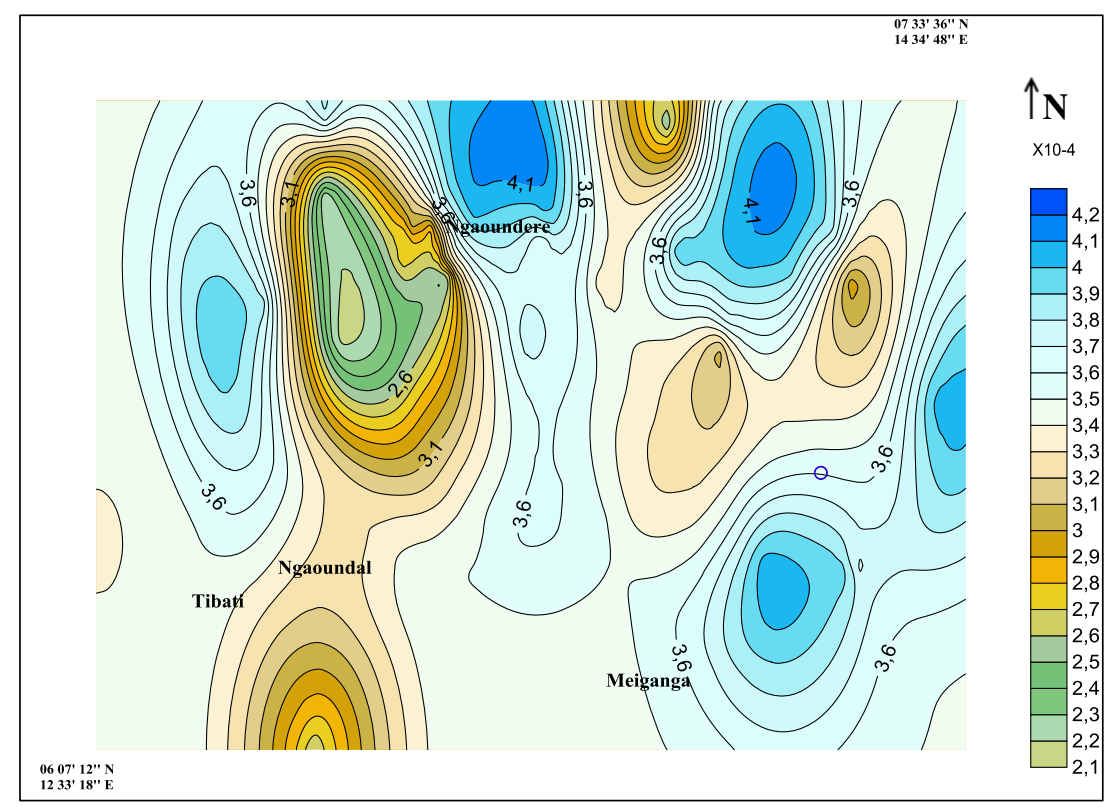

Figure 10. Thematic map of $K \sigma$.

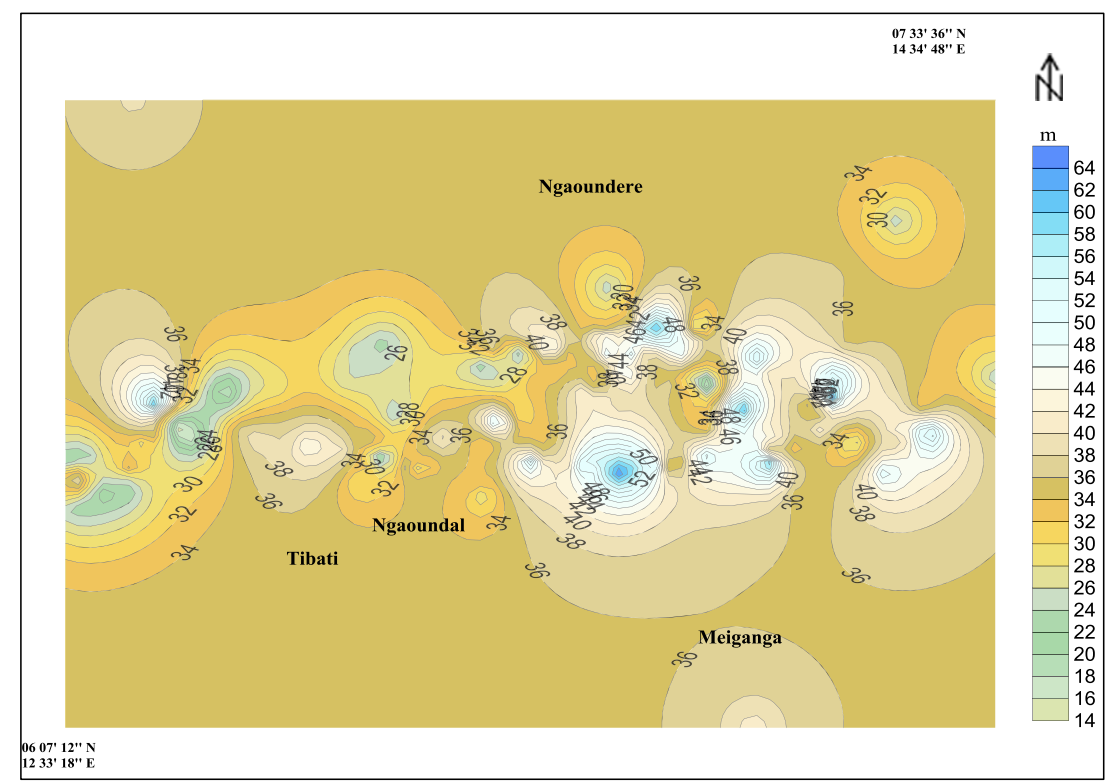

Figure 11. Thematic map of the depth where aquifer is situated.

\section{Conclusions}

Evaluation of hydraulic conductivity $K$ from surface resistivity measurements is possible, through developing relationships between the electrical Dar-Zarrouk parameters of $R$ or $S$ and hydraulic conductivity from pumping tests on existing boreholes in the Pan-African context. This study reveals that Pan-African aquifers are characterized by a depth ranged between 7 and $83 \mathrm{~m}$ with an average of $37 \mathrm{~m}$, a transverse conductance ranged from 0.004 to $5.25 \Omega^{-1}$ with an average of $0.61 \Omega^{-1}$, a resistivity ranged from 3 to $825 \Omega \mathrm{m}$ with an average of $228 \Omega \mathrm{m}$, a transmissivity ranged between 0.46 and $46.02 \mathrm{~m}^{2} /$ day and a hydraulic conductivity ranged from 0.012 to $1.677 \mathrm{~m} /$ day with an average of $0.465 \mathrm{~m} /$ day.

\section{Acknowledgements}

The first author would like to thank Dr Atangana Kouna Basile, Cameroonian Minister of Water Resources and Energy, for the permission to access 
to the archives and records of all his national and regional services.

\section{References}

Anomohanran O 2013 Geophysical investigation of groundwater potential in Ukelegbe, Nigeria; J. Appl. Sci. 13 119-125.

Arétouyap Z, Njandjock Nouck P, Bisso D, Nouayou R, Lengué B and Lepatio Tchieg A 2014 Climate variability and its possible interactions with water resources in central Africa; J. Appl. Sci. 14(19) 2219-2233.

Asfahani J 2007 Neogene aquifer properties specified through the interpretation of electrical sounding data, Salamiyeh region, central Syria; Hydrol. Process. 21 2934-2943.

Asfahani J 2011 The role of geoelectrical DC methods in determining the subsurface tectonic features: Case studies from Syria; In: Tectonics (ed.) Damien Closson, Tech. Europe: Rijeka, pp. 275-302.

Asfahani J 2012 Quaternary aquifer transmissivity in semiarid region in Khanasser Valley, northern Syria; Acta Geophys 60 1143-1158.

Asfahani J 2013 Groundwater potential estimation deduced from vertical electrical sounding measurements in the semi-arid Khanasser Valley region, Syria; Hydrol. Sci. J. 58 468-482.

Asfahani J 2014 Hydraulic conductivity estimation by using an approach based on vertical electrical soundings in the semi-arid Khanasser Valley Region, Syria, Environ. Earth Sci. (submitted).

Athavale R N, Rangarajan R and Murlidharan D 1992 Measurement of natural recharge in India; J. Geol. Soc. India $39235-244$.

Chandra S, Ananda Rao V and Singh V S 2004 A combined approach of Schlumberger and axial pole-dipole configurations for groundwater exploration in hard rock areas; Curr. Sci. 86 1437-1443.

Croft M G 1971 A method of calculating permeability from electric logs; In: US Geological Survey Staff, Geological Survey Research 1971, Chapter B. US Geological Survey Professional Paper 750-B, US Geological Survey: B265-B269.

Dobrin M B 1976 Introduction to geophysical prospecting (McGraw-Hill: New-York), 144p.

Emenike E A 2001 Geophysical exploration for groundwater in a sedimentary environment: A case study from Nanka over Nanka formation in Anambra Basin south-eastern Nigeria; Global J. Pure Appl. Sci. 7 254-262.

Frohlich R K, Fisher J J and Summerly E 1996 Electrical hydraulic conductivity correlation in fractured crystalline bedrock: Central Landfil, Rhode Island, USA; J. Appl. Geophys. 35 249-259.
Goovaerts P 1997 Geostatistics for natural resources evaluation; Oxford University Press, Applied Geostatistics Series, 365p.

Gorai A K and Kumar S 2013 Spatial distribution analysis of groundwater quality index using GIS: A case study of Ranchi Municipal Corporation (RMC) area; Geoinfor. Geostat: An overview 1(2), http://dx.doi.org/10.4172/ 2327-4581.1000105.

Huntley D 1986 Relation between permeability and electrical resistivity in granular aquifer; Ground Water $\mathbf{2 4}$ $466-475$.

Jones P H and Bufford T B 1951 Electric logging applied to groundwater exploration; Geophysics 1 115-139.

Kelly W E 1977 Geoelectric sounding for estimating aquifer hydraulic conductivity; Ground Water 15 420-424.

Mazáč O and Landa I 1979 On determination of hydraulic conductivity and transmissivity of granular aquifers by vertical electric sounding; J. Geol. Sci. 16 123-139.

Nejad 2009 Geoelectric investigation in the aquifer characteristics and groundwater potential in Behbahan Azad University farm, Khuzestan Province, Iran; J. Appl. Sci. 9 3691-3698.

Scarascia S 1976 Contributions of geophysical methods to the management of water resources; Geoexploration 14 $265-266$.

Segalen P 1967 Les sols et la géomorphologie du Cameroun; Cahier ORSTOM-Série Pédologie 5 137-187.

Toteu S F, Ngako V, Affaton P, Nnange J M and Njanko T H 2000 Pan-African tectonic evolution in central and southern Cameroon: Transpression and transtension during sinistral shear movements; J. African Earth Sci. 36 207-214.

Toteu S F, Penaye J and Poudjom Djomani Y 2004 Geodynamic evolution of the Pan-African belt in central Africa with special reference to Cameroon; Can. J. Earth Sci. 41 73-85.

Ungemach P, Mostaghimi F and Dupart A 1969 Essais de détermination du coefficient d'emmagasinement en nappe libre, application à la nappe alluviale du Rhin; Bulletin de l'Association Internationale d'Hydrologie Scientifique 14 169-190.

Vincenz S A 1968 Resistivity investigations of limestone aquifers in Jamaica; Geophysics 33 980-994.

Yang C and Lee V 2002 Using direct current resistivity sounding and geostatistics to aid in hydrogeological studies in the Choshuichi Alluvial Fan, Taiwan; Ground Water 40 165-173.

Zohdy A A R 1989 A new method for the automatic interpretation of Schlumberger and Wenner sounding curves; Geophysics 54 245-253.

Zohdy A A R and Bisdorf R J 1989 Schlumberger sounding data processing and interpretation program; US Geological Survey, Denver, 74p. 